\title{
CARACTERÍSTICAS DE LOS VÍDEOS EN ESPAÑOL PUBLICADOS EN YOUTUBE SOBRE LA VACUNA CONTRA EL VIRUS DEL PAPILOMA HUMANO
}

\author{
José Tuells (1), Pedro Javier Martínez-Martínez (1), José Luis Duro-Torrijos (1), \\ Pablo Caballero (1), Paula Fraga-Freijeiro (2) y Vicente Navarro-López (3).
}

(1) Cátedra de Vacunología "Balmis" UA-FISABIO. Universidad de Alicante. Alicante

(2) Charing Cross Hospital. London

(3) Unidad de Enfermedades Infecciosas. Hospital del Vinalopó. Elche

\section{RESUMEN}

Fundamentos: Internet constituye un recurso de búsqueda de información relacionada con la salud. El objetivo de este trabajo fue conocer las características de los vídeos en idioma español de YouTube relacionados con la vacuna contra el virus del papiloma humano (VPH).

Métodos: Se realizó un estudio observacional a partir de una búsqueda en YouTube el 26 de julio de 2013, con las palabras claves: "vacuna virus papiloma humano", "vacuna VPH", "vacuna Gardasil", "vacuna Cervarix". Se establecieron categorías por tipo, fuente de publicación y predisposición favorable o no hacia la vacuna. Se registró el número de visitas, tiempo de duración de los videos y origen de los 20 vídeos más visitados.

Resultados. Se encontraron 1.080 videos registrados, 170 fueron seleccionados y clasificados como: noticias locales ( $\mathrm{n}=39 ; 37$ favorables, 2 desfavorables; 2:06:29; 42972 visitas), noticias nacionales $(\mathrm{n}=32 ; 30 / 2 ; 1: 49: 27 ; 50138$ visitas), creados por subscritores de YouTube $(\mathrm{n}=21 ; 13 / 8 ; 2: 50: 35 ; 144655$ visitas $)$, entrevistas $(\mathrm{n}=21 ; 20 / 1$; $1: 44: 39 ; 10991$ visitas), anuncios ( $\mathrm{n}=21 ; 19 / 2 ; 0: 27: 05 ; 28435$ visitas), conferencias ( $\mathrm{n}=17 ; 15 / 2 ; 3: 25: 39 ; 27206$ visitas), documentales $(\mathrm{n}=16 ; 12 / 4 ; 2: 11: 31 ; 30629$ visitas $)$, y noticias internacionales $(\mathrm{n}=3$; $3 / 0 ; 0: 11: 33 ; 1667$ visitas). De los 20 videos más reproducidos predominan los favorables a la vacunación $(\mathrm{n}=12 ; 0: 43: 43 ; 161.789$ visitas) frente a los desfavorables $(\mathrm{n}=8 ; 2: 44: 14 ; 86.583$ visitas $)$

Conclusiones. Predominan los videos que tiene una opinión favorable hacia la vacuna contra el VPH, aunque los videos de contenido negativo son los más extensos y reproducidos.

Palabras clave: Papiloma virus humano. Vacunas contra papilomavirus, YouTube. Internet .

Correspondencia

José Tuells

Cátedra de Vacunología "Balmis" UA-FISABIO.

Facultad de Ciencias de la Salud

Campus de San Vicente Raspeig

Ap.99. E-03080 Alicante

Correo electrónico: tuells@ua.es

\section{ABSTRACT \\ Characteristics of the Videos in Spanish Posted on Youtube about Human Papillomavirus Vaccines}

Background. Internet is a resource to search for health-related information. The aim of this work was to know the content of the videos in Spanish language of YouTube related to the vaccine against the human papilloma virus (HPV).

Metthods. An observational study was conducted from a search on YouTube on 26th July 2013 by using keywords such as: "human papilloma virus vaccine", "HPV vaccine", "Gardasil vaccine", "Cervarix vaccine". Different categories were established according to: the type of vaccine, the published source and the favorable or unfavorable predisposition towards the human papillomavirus vaccination. The number of visits and the duration of the videos were gathered, with analysis of variables in the 20 most visited videos.

Results. A total of 170 videos were classified like: local news $(\mathrm{n}=39 ; 37$ favorable, 2 unfavorable; $2: 06: 29 ; 42972$ visits), national news ( $\mathrm{n}=32 ; 30 / 2 ; 1: 49: 27 ; 50138$ visits), created by YouTube subscribers $(\mathrm{n}=21 ; 21 / 1 ; 1: 44: 39 ; 10991$ visits $)$, advertisements $(\mathrm{n}=21$; $19 / 2 ; 0: 27: 05 ; 28435$ visits), conferences ( $n=17 ; 15 / 2 ; 3: 25: 39 ; 27206$ visits), documentaries ( $n=16 ; 12 / 4 ; 2: 11: 31 ; 30629$ visits). From all of the 20 most viewed YouTube videos predominated those which were favorable to the vaccination ( $\mathrm{n}=12 ; 0: 43: 43 ; 161789$ visits) against the unfavorable ( $\mathrm{n}=8 ; 2: 44: 14 ; 86583$ visits).

Conclusions. Most of the videos have a favorable opinion towards HPV vaccine, although videos with a negative content were the longest and most viewed.

Keywords: Human papillomavirus. Papillomavirus vaccines YouTube.Internet. 


\section{INTRODUCCIÓN}

El virus del papiloma humano (VPH) produce una de las infecciones de transmisión sexual más frecuentes en el mundo, especialmente en mujeres jóvenes sexualmente activas. Es, además, un agente causal relacionado con el cáncer cervicouterino, anal y de pene, así como de verrugas genitales tanto en hombres como mujeres ${ }^{1,2}$.

El conocimiento de la etiología viral del cáncer de cuello uterino ha permitido el desarrollo de una estrategia de prevención primaria mediante vacunas profilácticas ${ }^{3,4}$. En la actualidad se comercializan dos para combatir el VPH, una bivalente, Cervarix ${ }^{\circledR}$, y otra cuadrivalente, Gardasil ${ }$. Aunque buena parte de la literatura científica las muestra como seguras y bien toleradas ${ }^{4}$, existe cierta controversia social en cuanto a su seguridad, eficacia, coste económico y otras cuestiones médico-sociales ${ }^{5-7}$.

Los escasos conocimientos sobre las infecciones de transmisión sexual, en especial las relacionadas con el VPH, pueden afectar a las coberturas vacunales ${ }^{8}$. La información recibida a través del consejo médico puede aumentar la aceptación de la vacuna ${ }^{9,10}$ otorgándole, de este modo, un interés relevante a las estrategias de comunicación para promover la vacunación. Aun más, si cabe, en una sociedad cada vez más autónoma a la hora de adquirir información ${ }^{11}$.

Internet ha modificado el proceso de comunicación social, transformando los canales de participación médico-científicos. Las revistas profesionales, organizaciones de salud, sociedades científicas y los pacientes recurren a las redes sociales (YouTube, Twitter, Facebook) para divulgar o recibir información ${ }^{12}$.

Entre los portales disponibles destaca YouTube, un sitio Web, fundado en febrero de 2005, que se caracteriza por ser un recurso gratuito de intercambio de vídeos, una comunicación bidireccional que permi- te interactuar en una comunidad virtual y compartir puntos de vista alternativos ${ }^{13}$. En la actualidad, con más de 100 millones de vídeos, YouTube es uno de los sitios Web más frecuentados a nivel mundial ${ }^{14}$, con una capacidad de difusión que puede incidir en el campo de la educación sanitaria como fuente de mensajes de comunicación en el ámbito de la salud que no debe ser subestimada ${ }^{15}$, pudiendo actuar como modulador en la toma de decisiones a la hora de aceptar o no la vacuna contra el $\mathrm{VPH}^{16}$.

El objetivo de este trabajo fue conocer las características de los vídeos de YouTube en idioma español relacionados con la vacuna contra el virus del papiloma humano.

\section{MATERIAL Y MÉTODOS}

Diseño. Se llevó a cabo un estudio observacional centrado en la valoración cuantitativa y cualitativa de los vídeos publicados en el sitio Web YouTube (www.youtube. com) con temática relacionada con la vacuna frente al VPH mediante una búsqueda realizada el 26 de julio de 2013, utilizando las siguientes palabras claves para su exploración: "vacuna virus papiloma humano", "vacuna VPH", "vacuna Gardasil" y "vacuna Cervarix". La búsqueda se efectuó para cada palabra clave de forma independiente, sin la utilización de operadores booleanos. Los vídeos fueron descargados y almacenados en una base de datos. Su análisis se realizó inmediatamente después de su obtención, estableciéndose un conjunto de criterios de exclusión (figura 1) que consistieron en: vídeos que estuvieran en un idioma distinto al español, vídeos duplicados, vídeos fraccionados en varias partes, como por ejemplo "Construyendo ciencia -vacuna anti-HPV. Mitos y verdades. Parte $3^{17}$. En estas circunstancias sólo se tuvo en cuenta el video con más antigüedad en YouTube. Finalmente, en una última criba fueron eliminados los vídeos irrelevantes, que carecían expresamente de información relacionado con los términos de la búsqueda. Tres de los investigadores visionaron de manera 
independiente los vídeos resultantes de la selección final y valoraron sus contenidos clasificándolos como positivos o negativos según la presentación que efectuaban de la vacunación frente al VPH. Se utilizó una metodología similar a la utilizada por Ache et $a l^{18}$, incluyendo un análisis de concordancia (índice Kappa) entre los distintos evaluadores que no obtuvo discrepancias $(100 \%$ de acuerdo $\mathrm{K}=1,0)$.

Análisis estadístico. Los vídeos se categorizaron según el tipo de publicación en: noticias (locales, nacionales o internacionales), anuncios, documentales, entrevistas, conferencias y material exclusivo de YouTube de creación propia, es decir, elaborado por el subscriptor.

Las noticias se clasificaron según su objetivo de difusión como locales (provenientes de medios de comunicación de carácter provincial o autonómico), nacionales o internacionales. Los anuncios eran vídeos con una tendencia comercial. Los documentales eran vídeos de gran variedad narrativa y gráfica que plasmaban los beneficios y/o desventajas de la vacuna. Las entrevistas mostraban un diálogo con la finalidad de complementar la información referente a la vacuna contra el VPH, entre las que destacaban las realizadas a expertos e investigadores. Las conferencias procedían de diferentes foros académicos realizados en su mayoría por expertos.

Se registró la fuente de publicación de cada video. Se anotó el número de visitas recibidas, la duración (en minutos y segundos) de cada video, la fecha en que fueron publicados y el país de publicación. Se calculó el número total de reproducciones y el número total de minutos del conjunto de vídeos de la muestra.

\section{RESULTADOS}

De un total de 1.080 vídeos registrados, fueron finalmente seleccionados y analizados 170, tras aplicar los criterios de exclusión. Se descartaron 108 vídeos por estar en alguna lengua distinta al español, 186 vídeos fraccionados, 607 por estar duplicados, y 9 por tener contenidos irrelevantes (figura 1).

De los vídeos analizados 149 (87,6\%) mostraron una opinión favorable respecto a la vacuna contra el VPH, frente a los vídeos con posiciones desfavorables que fueron $21(12,4 \%)$ (tabla 1).

El número total de vídeos según el tipo de publicación y con posicionamiento positivo hacia la vacunación siguió el siguiente orden: noticias locales $(n=39,37 / 39$ favorables a la vacuna contra el VPH). Noticias nacionales $(n=32,30 / 32)$. Vídeos creados por los subscritores de YouTube $(n=21,13 / 21)$. Entrevistas $(n=21,20 / 21)$. Anuncios $(n=21,19 / 21)$. Conferencias $(n=17,15 / 17)$. Documentales $(n=16$, 12/16) (tabla 1).

La duración de los vídeos osciló entre 9" y 86 '22" siendo la duración media de 2'52". La suma de todos ellos ascendió a 886'58', de los cuales 679'48' eran propicios a la vacunación contra el VPH, frente a 207'10" que mostraron una clara oposición. Los vídeos con un contenido negativo, con una duración media de 4'15", fueron más extensos que las emisiones positivas, cuya duración media fue de 2'41'.

El número de reproducciones de los vídeos analizados osciló entre 9 y 48.389. El total de visitas fue de 336.693 visitas, de las cuales $237.153(70,44 \%)$ correspondieron a posiciones favorables hacia la vacuna contra el VPH, frente a $99.540(29,56 \%)$ con posturas en contra. La media de accesos a las emisiones con una inclinación positiva fue de 262 y de 1.051 para los vídeos con representación negativa (tabla 1).

Atendiendo a la fuente de publicación, 46 $(27,06 \%)$ vídeos procedían de los ministerios de salud de diversos países hispanohablantes; 38 (22,35\%) de facultativos; $32(18,82 \%)$ otro personal sanitario; 24 $(14,12 \%)$ de los medios de información y/o periodistas; $13(7,65 \%)$ de personas anóni- 
Figura 1

Diagrama de flujo para la selección de los videos en YouTube de la vacuna VPH.

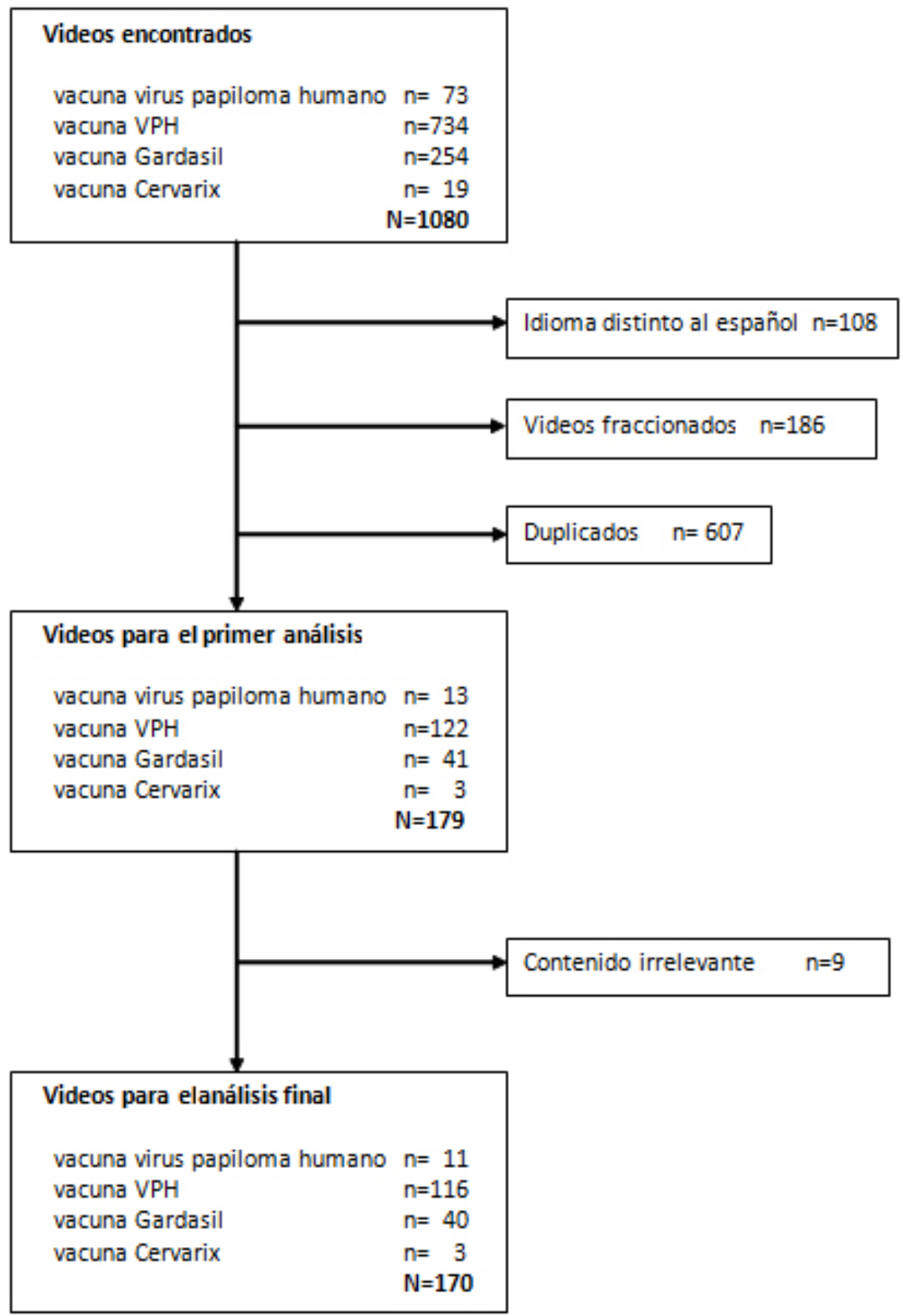




\begin{tabular}{|c|c|c|c|c|c|c|c|c|c|}
\hline \multicolumn{10}{|c|}{$\begin{array}{c}\text { Tabla } 1 \\
\text { Resultados y categorización según tipo de publicación }\end{array}$} \\
\hline \multirow[b]{2}{*}{ Tipo } & \multicolumn{3}{|c|}{ Positivos } & \multicolumn{3}{|c|}{ Negativos } & \multicolumn{3}{|c|}{ Total } \\
\hline & $\begin{array}{c}\mathrm{n} \\
(\%)\end{array}$ & $\begin{array}{c}\text { Duración } \\
(\%)\end{array}$ & $\begin{array}{c}\text { Reproducciones } \\
(\%)\end{array}$ & $\begin{array}{c}\mathrm{n} \\
(\%)\end{array}$ & $\begin{array}{c}\text { Duración } \\
(\%)\end{array}$ & \begin{tabular}{|c|} 
Reproducciones \\
$(\%)$
\end{tabular} & $\begin{array}{c}\mathrm{n} \\
(\%)\end{array}$ & $\begin{array}{c}\text { Duración } \\
(\%)\end{array}$ & $\begin{array}{c}\text { Reproducciones } \\
(\%)\end{array}$ \\
\hline Locales & $\begin{array}{r}37 \\
(21,8) \\
\end{array}$ & $\begin{array}{r}2: 02: 13 \\
(13,8)\end{array}$ & $\begin{array}{r}42.698 \\
(12,7) \\
\end{array}$ & $\begin{array}{r}2 \\
(1,2)\end{array}$ & $\begin{array}{r}0: 04: 16 \\
(0,5) \\
\end{array}$ & $\begin{array}{r}274 \\
(0,1) \\
\end{array}$ & $\begin{array}{r}39 \\
(22,9)\end{array}$ & $\begin{array}{r}2: 06: 29 \\
(14,3) \\
\end{array}$ & $\begin{array}{r}42.972 \\
(12,8) \\
\end{array}$ \\
\hline Nacionales & $\begin{array}{r}30 \\
(17,6) \\
\end{array}$ & $\begin{array}{r}1: 45: 05 \\
(11,8) \\
\end{array}$ & $\begin{array}{r}50.044 \\
(14,9) \\
\end{array}$ & $\begin{array}{r}2 \\
(1,2)\end{array}$ & $\begin{array}{r}0: 04: 22 \\
(0,5)\end{array}$ & $\begin{array}{r}94 \\
(0,0) \\
\end{array}$ & $\begin{array}{r}32 \\
(18,8) \\
\end{array}$ & $\begin{array}{r}1: 49: 27 \\
(12,3)\end{array}$ & $\begin{array}{r}50.138 \\
(14,9) \\
\end{array}$ \\
\hline Internacionales & $\begin{array}{r}3 \\
(1,8) \\
\end{array}$ & $\begin{array}{r}0: 11: 33 \\
(1,3) \\
\end{array}$ & $\begin{array}{r}1.667 \\
(0,5) \\
\end{array}$ & $\begin{array}{r}0 \\
(0,0) \\
\end{array}$ & $\begin{array}{r}0: 00: 00 \\
(0,0)\end{array}$ & $\begin{array}{r}0 \\
(0,0) \\
\end{array}$ & $\begin{array}{r}3 \\
(1,8) \\
\end{array}$ & $\begin{array}{r}0: 11: 33 \\
(1,3) \\
\end{array}$ & $\begin{array}{r}1.667 \\
(0,5) \\
\end{array}$ \\
\hline Creación propia & $\begin{array}{r}13 \\
(7,6) \\
\end{array}$ & $\begin{array}{r}1: 03: 54 \\
(7,2) \\
\end{array}$ & $\begin{array}{r}77.505 \\
(23,0) \\
\end{array}$ & $\begin{array}{r}8 \\
(4,7) \\
\end{array}$ & $\begin{array}{r}1: 46: 41 \\
(12,0) \\
\end{array}$ & $\begin{array}{r}67.150 \\
(19,9) \\
\end{array}$ & $\begin{array}{r}21 \\
(12,4) \\
\end{array}$ & $\begin{array}{r}2: 50: 35 \\
(19,2)\end{array}$ & $\begin{array}{r}144.655 \\
(43,0)\end{array}$ \\
\hline Entrevistas & $\begin{array}{r}20 \\
(11,8) \\
\end{array}$ & $\begin{array}{r}1: 38: 10 \\
(11,1) \\
\end{array}$ & $\begin{array}{r}6.712 \\
(2,0) \\
\end{array}$ & $\begin{array}{r}1 \\
(0,6) \\
\end{array}$ & $\begin{array}{r}0: 06: 29 \\
(0,7) \\
\end{array}$ & $\begin{array}{r}4.279 \\
(1,3) \\
\end{array}$ & $\begin{array}{r}21 \\
(12,4) \\
\end{array}$ & $\begin{array}{r}1: 44: 39 \\
(11,8) \\
\end{array}$ & $\begin{array}{r}10.991 \\
(3,3) \\
\end{array}$ \\
\hline Anuncios & $\begin{array}{r}19 \\
(11,2) \\
\end{array}$ & $\begin{array}{r}0: 19: 56 \\
(2,2) \\
\end{array}$ & $\begin{array}{r}25.547 \\
(7,6) \\
\end{array}$ & $\begin{array}{r}2 \\
(1,2)\end{array}$ & $\begin{array}{r}0: 07: 09 \\
(0,8) \\
\end{array}$ & $\begin{array}{r}2.888 \\
(0,9) \\
\end{array}$ & $\begin{array}{r}21 \\
(12,4) \\
\end{array}$ & $\begin{array}{r}0: 27: 05 \\
(3,05)\end{array}$ & $\begin{array}{r}28.435 \\
(8,4) \\
\end{array}$ \\
\hline Conferencias & $\begin{array}{r}15 \\
(8,8) \\
\end{array}$ & $\begin{array}{r}2: 54: 34 \\
(19,7) \\
\end{array}$ & $\begin{array}{r}20.348 \\
(6,0) \\
\end{array}$ & $\begin{array}{r}2 \\
(1,2) \\
\end{array}$ & $\begin{array}{r}0: 31: 05 \\
(3,5) \\
\end{array}$ & $\begin{array}{r}6.858 \\
(2,0) \\
\end{array}$ & $\begin{array}{r}17 \\
(10,0) \\
\end{array}$ & $\begin{array}{r}3: 25: 39 \\
(23,2) \\
\end{array}$ & $\begin{array}{r}27.206 \\
(8,1) \\
\end{array}$ \\
\hline Documentales & $\begin{array}{r}12 \\
(7,1) \\
\end{array}$ & $\begin{array}{r}1: 24: 23 \\
(9,5) \\
\end{array}$ & $\begin{array}{r}12.632 \\
(3,8)\end{array}$ & $\begin{array}{r}4 \\
(2,4)\end{array}$ & $\begin{array}{r}0: 47: 08 \\
(5,3) \\
\end{array}$ & $\begin{array}{r}17.997 \\
(5,3) \\
\end{array}$ & $\begin{array}{r}16 \\
(9,4) \\
\end{array}$ & $\begin{array}{r}2: 11: 31 \\
(14,8\end{array}$ & $\begin{array}{r}30.629 \\
(9,1)\end{array}$ \\
\hline Total & $\begin{array}{r}149 \\
(87,6) \\
\end{array}$ & $\begin{array}{r}11: 19: 48 \\
76,6 \\
\end{array}$ & $\begin{array}{r}237.153 \\
(70,4)\end{array}$ & $\begin{array}{r}21 \\
(12,4)\end{array}$ & $\begin{array}{r}3: 27: 10 \\
(23,4)\end{array}$ & $\begin{array}{r}99.540 \\
(29,6)\end{array}$ & $\begin{array}{r}170 \\
(100,0)\end{array}$ & $\begin{array}{r}14: 46: 58 \\
(100,0)\end{array}$ & $\begin{array}{r}336.693 \\
(100,0)\end{array}$ \\
\hline
\end{tabular}

mas; 7 (4,12\%) de centros universitarios; 7 $(4,12 \%)$ de afectados por efectos adversos de la vacuna; y $3(1,76 \%)$ de la industria farmacéutica (tabla 2).

Los 20 vídeos más reproducidos contaron con un total de 248.372 visitas, con un rango de entre 4.559 y 48.389 (tabla 3). Predominaron los vídeos con una opinión favorable a la vacunación, de los cuales $12(60 \%)$ contaron un total de 161.789 (65\%) visitas, frente a $8(40 \%)$ vídeos con un tendencia contraria hacia la vacuna $\mathrm{VPH}$, visualizados 86.583 $(34,7 \%)$ veces. Prevalecieron los vídeos de creación propia $(8,3 / 8$ con representación positiva hacia la vacuna contra el VPH) y documentales $(4,2 / 2)$. La duración de los 20 vídeos ascendió a 197'57”, con una duración

Tabla 2

Número de videos y porcentaje según la fuente de publicación

\begin{tabular}{|c|c|c|c|c|c|c|}
\hline Fuente & $\mathrm{N}^{\mathrm{o}}$ de videos & $\%$ & Positivos & $\%$ & Negativos & $\%$ \\
\hline Ministerio Salud & 46 & 27,06 & 45 & 30,20 & 1 & 4,76 \\
\hline Facultativos & 38 & 22,35 & 34 & 22,82 & 4 & 19,05 \\
\hline Personal salud & 32 & 18,82 & 30 & 20,13 & 2 & 9,52 \\
\hline Periodistas & 24 & 14,12 & 22 & 14,77 & 2 & 9,52 \\
\hline Anónimo & 13 & 7,65 & 8 & 5,37 & 5 & 23,81 \\
\hline Universidades & 7 & 4,12 & 7 & 4,70 & 0 & 0 \\
\hline Afectados/daños & 7 & 4,12 & 0 & 0 & 7 & 33,33 \\
\hline I. Farmacéutica & 3 & 1,76 & 3 & 2,01 & 0 & 0 \\
\hline TOTAL & 170 & 100 & 149 & 100 & 21 & 100 \\
\hline
\end{tabular}




\begin{tabular}{|c|c|c|c|c|c|c|c|}
\hline \multicolumn{8}{|c|}{$\begin{array}{c}\text { Tabla } 3 \\
\text { Análisis de los } 20 \text { videos en español sobre la vacuna contra el VPH más vistos en YouTube }\end{array}$} \\
\hline Orden & Título & Visionados & Duración & Fecha & Opinión & Tipo & País \\
\hline 1 & Tratamiento y recomendaciones sobre el virus papiloma humano & 48.389 & $0: 03: 24$ & $31 / 03 / 2011$ & Positiva & Creación propia & Colombia \\
\hline 2 & Vacuna del papiloma virus 01 & 34.479 & $0: 02: 22$ & $05 / 11 / 2007$ & Positiva & noticia nacional & España \\
\hline 3 & Vacuna contra el Virus del Papiloma Humano (VPH) & 23.663 & $0: 03: 28$ & $01 / 06 / 2008$ & Negativa & Creación propia & España \\
\hline 4 & vax mortis: vacunas que matan la verdad de la vacuna... & 19.783 & $1: 26: 22$ & $04 / 10 / 2012$ & Negativa & Creación propia & México \\
\hline 5 & dra. florencia borgarello (hpv - parte 2) santa fé & 14.971 & $0: 13: 42$ & $16 / 03 / 2011$ & Positiva & Conferencia & Argentina \\
\hline 6 & Vacuna VPH Gardasil Muerte Subita & 13.291 & $0: 04: 58$ & $25 / 06 / 2011$ & Negativa & Creación propia & Argentina \\
\hline 7 & Prevenir el Cáncer de Cuello de Utero. TV3 Cataluña 04-02-2010 & 10.534 & $0: 02: 02$ & $27 / 03 / 2010$ & Positiva & Noticia local & España \\
\hline 8 & La vacuna del Papiloma Humano estará disponible en septiembre & 9.791 & $0: 01: 31$ & $29 / 07 / 2008$ & Positiva & Noticia local & España \\
\hline 9 & Vacuna GDF a adolescentes contra papiloma & 8.559 & 0:01:30 & $19 / 01 / 2010$ & Positiva & Creación propia & México \\
\hline 10 & Vacuna del papiloma humano (HPV) Gardasil alerta vaccínea... & 7.360 & $0: 13: 16$ & $04 / 12 / 2011$ & Negativa & Documental & España \\
\hline 11 & Vacuna contra el cáncer de útero, en "La noche al día" & 6.986 & $0: 00: 36$ & $04 / 12 / 2008$ & Positiva & Noticia local & España \\
\hline 12 & Vacuna para Virus de Papiloma Humano (VPH) & 6.528 & $0: 07: 21$ & $06 / 07 / 2011$ & Positiva & Creación propia & México \\
\hline 13 & Vacuna Papiloma Verdades y Mentiras parte 1 & 6.440 & $0: 28: 03$ & $18 / 09 / 2009$ & Negativa & conferencia & España \\
\hline 14 & "El Cancer de Cuello Uterino se puede prevenir". Acuerdo Vital.avi & 6.300 & $0: 02: 51$ & $01 / 10 / 2010$ & Positiva & anuncio & Venezuela \\
\hline 15 & Vacuna Contra el Papiloma y sus efectos secundarios... & 6.232 & $0: 09: 36$ & $21 / 02 / 2012$ & Negativa & documental & Rep.Dominicana \\
\hline 16 & La Vacuna contra Virus del Papiloma Humano evita el cáncer cuello... & 5.494 & $0: 04: 36$ & $22 / 04 / 2013$ & Positiva & documental & Colombia \\
\hline 17 & Spot: Lanzamiento Vacunación VPH & 5.199 & $0: 01: 58$ & $05 / 10 / 2011$ & Positiva & anuncio & Argentina \\
\hline 18 & efectos secundarios vacuna papiloma humano & 4.963 & $0: 03: 18$ & $17 / 09 / 2012$ & Negativa & creación propia & España \\
\hline 19 & VAX MORTIZ - Testimonio de Brittney Feist- Los Peligros de la... & 4.851 & 0:05:13 & $16 / 02 / 2012$ & Negativa & creación propia & México \\
\hline 20 & Vacuna del Papiloma Humano & 4.559 & $0: 01: 50$ & $26 / 05 / 2009$ & Positiva & documental & México \\
\hline
\end{tabular}


entre 36" y 86'22", los vídeos que contenían opiniones favorables sumaron un tiempo de 43'43", frente a los $164^{\prime} 14$ " de los vídeos con posicionamiento desfavorable.

Respecto al país de procedencia de elaboración se obtuvo el siguiente orden: España (8, 4/8 con representación positiva hacia la vacuna $\mathrm{VPH})$, México (5, 3/5), Argentina (3, $2 / 3)$, Colombia $(2,2 / 2)$, y por último Venezuela $(1,1 / 1)$ y Republica Dominicana (1, $1 / 1)$.

\section{DISCUSIÓN}

La mayoría de los vídeos analizados se muestran favorables a la vacuna, aunque los publicados con contenido negativo tienen una duración media y un número medio de visitas mayores. A medida que la vacuna contra el VPH se ha ido implantando y ha venido acompañándose de una cierta controversia, su representación en las redes sociales de Internet ha ido creciendo, como confirma este estudio en YouTube, donde los 20 vídeos más visitados se han publicado entre 2007 y 2013.

El análisis de los 170 vídeos de YouTube en español muestra que el $87,6 \%$ de éstos expresan una opinión favorable hacia la vacunación contra el VPH. Los resultados obtenidos se asemejan al estudio realizado en 2008 con vídeos publicados en lengua inglesa, en el que el $75 \%$ presentaban positivamente la vacunación $\mathrm{VPH}^{18} \mathrm{El}$ porcentaje de tratamiento positivo de la vacuna VPH es alto en ambos estudios y aún mayor en los vídeos en español. Sin embargo, su realización guarda una separación temporal de cinco años. La variabilidad del medio pone de manifiesto el sesgo temporal y el riesgo de establecer esa comparación, ya que una investigación más reciente indica una tendencia hacia las opiniones desfavorables en los vídeos de habla inglesa publicados en YouTube, donde representan el $51,7 \%{ }^{19}$.

No obstante, un estudio reciente, que analiza la información proporcionada en español por el motor de búsqueda Google en relación con la vacuna $\mathrm{VPH}$, revela un $72,2 \%$ de opiniones favorables en las páginas Web evaluadas ${ }^{20}$.

YouTube, como medio que permite al usuario obtener consejo médico, ofrece en ocasiones información sesgada por su falta de rigor científico ${ }^{20}$, un hecho que puede dar lugar a decisiones poco fundamentadas que afecten a la aceptación o no de la vacuna contra el VPH.

La presencia de información negativa en Internet en relación a la vacunación ${ }^{21,22}$, contrasta con los resultados de este estudio que proporcionan una perspectiva más alentadora. Se ha observado que los vídeos publicados por los propios subscriptores de YouTube son los que alcanzan el mayor número de reproducciones con una ligera ventaja para los de contenido positivo. Esta iniciativa de crear vídeos viene a mostrar la tendencia y voluntad existente en la sociedad por participar en el debate que rodea a la vacunación VPH y cómo las fuentes de información no están circunscritas a los gobiernos o a las agencias de salud pública ${ }^{19}$.

Resulta significativo que los vídeos publicados con opiniones negativas tienen una duración media mayor y un número medio de visitas también mayor que los de opiniones positivas. Estos resultados se refrendan en el análisis de los veinte vídeos más reproducidos, el cual muestra a España y México como los países que más información generan, con mayor número de vídeos y reproducciones que el resto de países de habla hispana.

La calidad de la información contenida en los vídeos se ha evaluado teniendo en cuenta el origen de la publicación, considerando la hipótesis que relaciona una mejor fiabilidad con el tipo de fuente. La mayoría de los vídeos publicados proceden de los ministerios de salud de cada país y de distintos sanitarios que son presentados como expertos por su calidad de especialistas (pediatras, ginecólogos, preventivistas). 
Estos colectivos presentan mayoritariamente de forma positiva la vacunación VPH. Mención aparte merece el origen de los vídeos con una posición negativa, cuya procedencia son las asociaciones de personas afectadas por efectos adversos de la vacuna o, en ocasiones, fuentes anónimas. Ningún país con el español como idioma oficial tiene implementados programas de compensación de daños por vacunas $^{23}$.

La exclusión de vídeos en otros idiomas diferentes al español circunscribe los resultados del estudio a su ámbito de influencia. Los criterios de categorización pueden tener un componente subjetivo, minimizado por el acuerdo de los investigadores en la clasificación de los vídeos. Puede considerarse como una limitación del estudio que se obtuvo y recopiló la información disponible en un momento concreto y que una característica de YouTube es su permanente variabilidad. Tampoco permite distinguir el tipo de población que accede a esta información.

La valoración positiva predominante en español en Youtube sobre la vacuna VPH debería monitorizarse con cortes temporales que permitieran evaluar las tendencias. El ejemplo de la literatura inglesa con su línea descendente debería ser orientativo para estimular esta iniciativa. Sería también muy interesante observar cómo se presentan y son valoradas en YouTube otro tipo de vacunas.

El estudio refleja un activismo en las redes sociales que opone valores positivos de la vacuna frente a argumentos de resistencia a la misma. Valorar la posible asociación entre niveles de cobertura vacunal y exposición a las redes sociales ofrecería una perspectiva más aquilatada sobre la influencia real de YouTube en la toma de decisiones sobre vacunas.

\section{BIBLIOGRAFÍA}

1. De-Regil LM, Palacios C, Ansary A, Kulier R, P1. Tota J, Chevarie-Davis M, Richardson LA, Devries M, Franco EL. Epidemiology and burden of HPV infection and related diseases: implications for prevention strategies. Prev Med. 2011;53 Suppl 1:S12-21
2. Genden EM, Sambur IM, de Almeida JR, Posner M, Rinaldo A, Rodrigo JP, et al. Human papillomavirus and oropharyngeal squamous cell carcinoma: what the clinician should know. Eur Arch Otorhinolaryngol. 2013;270:405-16

3. Garland SM, Smith J. Human papillomavirus vaccines: current status and future prospects. Drugs. 2010;70:1079-98

4. Pomfret TC, Gagnon JM, Gilchrist AT. Quadrivalent human papillomavirus (HPV) vaccine: a reviex of safety, efficacy, and pharmacoeconomics. J Clin Pharm Ther. 2011; 36:1-9

5. Martín-Llaguno M, Álvarez-Dardet C. La retirada de una campaña publicitaria para promoción de la vacuna tetravalente del virus del papiloma humano en España. Gac Sanit. 2010;24:75-7

6. Hilton S, Hunt K, Langan M, Bedford H, Petticrew $\mathrm{M}$. Newsprint media representations of the introduction of the HPV vaccination programme for cervical cancer prevention in the UK (2005-2008). Soc Sci Med. 2010;70:942-50

7. Vamos CA, McDermott RJ, Daley EM. The HPV vaccine: Framing the arguments FOR and AGAINST mandatory vaccination of all middle school girls. J Sch Health. 2008; 78:302-9

8. Chan SS, Yan Ng BK, Lo WK, Cheung TH, Hung Chung TK. Adolescent girls' attitudes on human papillomavirus vaccination. J Pediatr Adolesc Gynecol. 2009; 22:85-90

9. Brewer NT, Gottlieb SL, Reiter PL, McRee AL, Liddon N, Markowitz L. Longitudinal predictors of human papillomavirus vaccine initiation among adolescent girls in a high-risk geographic area. Sex Transm Dis. 2011;38:197-204

10. Reiter PL, Brewer NT, Gottlieb SL, McRee AL, Smith JS. Parents' health beliefs and HPV vaccination of their adolescent daughters. Soc Sci Med. 2009;69:475-80

11. Betsch C, Brewer NT, Brocard P, Davies P, Gaissmaier W, Haase N, et al. Opportunities and challenges of Web 2.0 for vaccination decisions. Vaccine. 2012;30:3727-33

12. Arcaro P, Mannocci A, Saulle R, Miccoli S, Marzui1lo C, La Torre G. Social martketing and public health. Ann Ig. 2013;25:247-62

13. Kata A. Anti-vaccine activists, Web 2.0, and the postmodern paradigm - An overview of tactics and tropes used online by the anti-vaccination movement. Vaccine. 2012;30:3778-89

14. Alexa: The Web Information Company. Top sites, [Online]. (Consultado el 13/07/2013) Disponible en: http://www.alexa.com/topsites 
15. Center for Disease Control and Prevention, "Social media guidelines and best practices" YouTube and other online video, 1610 2012. [Online]. (Consultado el 13/07/2013) Disponible en:

http://www.cdc.gov/SocialMedia/Tools/guidelines/ pdf/onlinevideo.pdf

16. Niedereppe J, Hornick RC, Kelly BJ, Frosch DL, Romantan A, Stevens RS, et al. Examining the dimensions of cancer-related information seeking and scanning behavior. Health Commun. 2007;22:153-67

17. Gasparutti L. Construyendo ciencia -vacuna anti-HPV. Mitos y verdades- Parte 3. (Consultado el 14/07/2013) Disponible en: http://www.youtube.com/ watch? $v=x n z k 3$ Y0Irv4

18. Ache KA, Wallace LS. Human papillomavirus vaccination coverage on YouTube. Am J Prev Med. 2008;35:389-92

19. Briones R, Nan X, Madden K, Waks L. When vaccines go viral: an analysis of HPV vaccine coverage on Youtube. Health Commun. 2012;27:478-85

20. Pías Peleteiro L, Cortés Bordoy J, Martinón Torres F. Dr. Google: What about the human papillomavirus vaccine? Hum Vaccin Immunother. 2013;9:1712-9

21. Bean SJ. Emerging and continuing trends in vaccine opposition website content. Vaccine. 2011;29:1874-80

22. Kata A. A postmodern Pandora's box: anti-vaccination misinformation on the Internet. Vaccine. 2010;28:1709-16

23. Tuells J. Razones para un programa de compensación de daños por acontecimientos adversos relacionados con vacunas en España. Med Clin. 2013; 140: 554-557. 